\title{
Editorial
}

\section{Kinematic Design of Manipulators}

The purpose of this special journal issue is to aggregate papers on design issues for the kinematic design of robots by looking at different subjects that can define open problems but new solutions both for design procedures and robot architectures. Kinematic design of manipulators can be understood as related to the definition and computation of the kinematic scheme of the structure of a robot, but it is also related to the procedures and algorithms that can be used and elaborated to determine a solution of mechanism schemes and their dimensions for a mechanical design of a robot. Therefore, papers have been selected on problems and new structures for robots as based on kinematic aspects but also algorithms for solving design problems for robotic architectures. Numerical aspects have been integrated not only with theoretical arguments but even with practical implementations and laboratory experiments.

We invited authors to presents their results from their activity in original research papers and surveys that can give an overview of the challenging problems and possibilities for the kinematic design of manipulators as well as together their successful applications in new and old areas.

This journal special issue contains 7 papers, that have been selected after peer review and cover several aspects of the wide field of kinematic design of robots.

I would like to express grateful thanks to the co-editors prof. Jian S. Dai from King's College in London and prof. R. Sandipan Bandyopadhyay from Indian Institute of Technology in Madras for having co-operated enthusiastically in advertising, organizing, and handling paper review for this special issue.

I thank also the authors, who have contributed with very interesting papers in several subjects, covering many fields of kinematic design of robots. I acknowledge them for their cooperation in revising papers in due time in agreement with reviewers' comments. I am grateful to the reviewers for the time and effort they spent in evaluating the papers with a very tighten schedule that has permitted the publication of this special issue.

I will like to thank the publisher and Editorial staff of this journal for accepting and helping the publication of this special issue, since the early step in 2009.

Marco Ceccarelli

(Guest Editor)

LARM: Laboratory of Robotics and Mechatronics DIMSAT; University of Cassino

Via Di Biasio 43, 03043 Cassino (Fr), Italy

Tel: +39-0776-2993663

E-mail: ceccarelli@unicas.it

Received: March 09, 2010

Revised: June 11, 2010

Accepted: June 19, 2010

(C) Marco Ceccarelli; Licensee Bentham Open.

This is an open access article licensed under the terms of the Creative Commons Attribution Non-Commercial License (http: //creativecommons.org/licenses/by$\mathrm{nc} / 3.0 /$ ), which permits unrestricted, non-commercial use, distribution and reproduction in any medium, provided the work is properly cited. 